\title{
Correlative Atomic Scale Characterisation of Secondary Carbides in M50 Bearing Steel
}

\author{
Sarah E. Hopkin ${ }^{1}$, Mohsen Danaie ${ }^{1}$, Gael Guetard ${ }^{2}$, Pedro Rivera-Diaz-del-Castillo ${ }^{2}$, Paul A. J. \\ Bagot $^{1}$, Michael P. Moody ${ }^{1 *}$ \\ 'Department of Materials, University of Oxford, Parks Road, Oxford OX1 3PH, UK \\ ${ }^{2}$ Department of Materials Science and Metallurgy, University of Cambridge 27 Charles Babbage \\ Road, Cambridge CB3 0FS, UK \\ *To whom correspondence should be addressed; E-mail: michael.moody@materials.ox.ac.uk
}




\title{
Correlative Atomic Scale Characterisation of Secondary Carbides in M50 Bearing Steel
}

\begin{abstract}
Correlative atom probe tomography (APT) and transmission electron microscopy (TEM) are used to characterise the microstructure and chemistry of carbide precipitation in M50 bearing steel. This is a prerequisite in establishing relationships between the microstructure and hydrogen embrittlement (HE) resistance. Secondary carbides are the focus of this study, as they play a major role in improving HE-resistance. Secondary carbides are observed in APT, with compositions close to $\mathrm{M}_{4} \mathrm{C}_{3}, \mathrm{M}_{2} \mathrm{C}$, and $\mathrm{M}_{3} \mathrm{C}$. Correlative TEM measured orientation relationships between the martensite matrix and carbides enabling the confirmation of $\mathrm{M}_{3} \mathrm{C}$ cementite precipitates in the corresponding APT reconstruction. Additionally, other precipitates observed in TEM were correlated to the $\mathrm{M}_{2} \mathrm{C}$ carbides in APT data. The $\mathrm{M}_{4} \mathrm{C}_{3}$ carbides are found to have a significantly lower volume fraction than the $\mathrm{M}_{2} \mathrm{C}$ carbides.
\end{abstract}

Keywords: M50 steel, atom probe tomography, transmission electron microscopy, correlative microscopy, bearing steels 


\section{Introduction}

Bearings are high-strength, friction-reducing components in many applications [1, 2]. To reduce wear, bearing environments contain lubricants, water and other fluids, which can lead to corrosion and hydrogen ingress [2, 3]. The hydrogen accelerates rolling-contact fatigue (RCF) via hydrogen embrittlement (HE) [4, 5]. The mechanisms of HE are not fully understood [6], making HE-accelerated bearing failure unpredictable [3].

Studies show only diffusible hydrogen contributes to HE $[7,8]$. Trapping the hydrogen using microstructural features such as secondary carbides can therefore reduce HE [9-11]. This is effective in low-carbon steels [3], however these alloys are not sufficiently hard to make effective bearings [11]. To optimise hydrogen resistance in bearing steels without decreasing hardness or high-temperature stability, it is essential to understand how carbide composition, number density and morphology affect these properties. First, an accurate method of characterising the carbide phases in current alloys must be developed. An M50-alloy will be used for this purpose.

M50 is a common through-hardening martensitic bearing steel used in jet engines and other high-temperature applications due to its excellent wear resistance, dimensional stability, and high Vickers hardness of 800 , which is retained to over $400^{\circ} \mathrm{C}[2,12,13]$. Three types of secondary carbides, $\mathrm{MC}, \mathrm{M}_{2} \mathrm{C}$ and $\mathrm{M}_{3} \mathrm{C}$ have been observed in atom probe field-ion microscopy (AP-FIM) studies of peak-aged high-speed steels with similar compositions to M50 [14, 15]. The coherent $\mathrm{M}_{2} \mathrm{C}$ carbides are most prevalent and give bearing steels their high hardness $[16,17]$.

It is important to determine the carbon content of these secondary carbides, as carbon vacancies are important hydrogen traps $[8,18]$. Substoichiometric carbides also improve resistance to RCF $[19,20]$. Bridge et al. [21] reported $\mathrm{MC}$ and $(\mathrm{Mo} 0.53 \mathrm{Fe} 0.20 \mathrm{Cr} 0.27)_{2} \mathrm{C}$ secondary carbides in peakaged M50, using an electrolytic extraction method. These results are only semi-quantitative as carbon was lost during the extraction process [21]. The calculations also assumed stoichiometric carbides, which may be inaccurate as MC carbides are often reported to have a composition closer 
to $\mathrm{M}_{4} \mathrm{C}_{3}[11,22-24]$, while carbon-deficient $\mathrm{M}_{2} \mathrm{C}$ has been observed in AP-FIM [14, 25]. This deficiency could be an AP-FIM artefact as a spatial overlap of the matrix and carbide signal was observed during analysis [14]. This suggests the composition may have been affected by local magnification-induced aberrations [26].

The relative abundances of the different carbides is also essential, as the hydrogen trapping capacity varies between carbides. $\mathrm{M}_{3} \mathrm{C}$ (cementite) and coherent $\mathrm{Mo}_{2} \mathrm{C}$ have similar trapping energies, while $\mathrm{M}_{4} \mathrm{C}_{3}$ carbides have a trapping energy almost three times higher (Table 1) [8]. In particular, secondary vanadium carbides are considered an attractive hydrogen trap for bearing steels as they are stable up to about $220^{\circ} \mathrm{C}$ and also increase the hardness [24, 27]. After electrolytically extracting and weighing the carbides, Bridge et al. [21] reported a higher weight percent of $\mathrm{M}_{2} \mathrm{C}$ secondary carbides, at 3.8-4.1 wt.\%, compared to 0.9-1.6 wt.\% for the $\mathrm{MC}$ secondary carbides. Again, these results are semi-quantitative.

To better determine the composition and relative abundances of these carbides, atom probe tomography (APT) will be the main characterisation technique as it has the high spatial resolution and excellent mass resolving power required for accurate nanoscale chemical analysis [26]. Diffraction contrast from transmission electron microscopy (TEM) will provide structural information about the carbide crystallography and coherency [28]. This crystallographic information is very difficult, often impossible, to identify using APT due to a combination of limited spatial resolution and the fact that not all atoms in the field-of-view are detected. Hence any crystallographic information provided by APT is at best limited. Complementary and correlative APT and TEM have been used to excellent effect in the characterisation of a range of microstructures in a variety of steels [48-50]. 


\section{Materials and Methods}

M50 samples were obtained from the Cambridge SKF University Technology Centre. A VIMVAR casting process was followed by hot-rolling and soft-annealing for two hours at $880^{\circ} \mathrm{C}$. The ingot was then cooled to $600^{\circ} \mathrm{C}$ over 11 hours. A five-minute austenisation in a vacuum furnace at $1105^{\circ} \mathrm{C}$ was followed by quenching to room temperature. Three tempering cycles were performed at $545^{\circ} \mathrm{C}$, for two hours each, with two hour cryogenic treatments between the tempering cycles. The bulk measured composition is outlined in Table 2. Carbon was measured using combustion infra-red detection (LECO instruments) while the other elements were measured by x-ray fluorescence (Thermo Fisher Advant XP analyser).

APT Samples were prepared using a standard two-stage electropolishing procedure [26]. A $25 \%$ percholoric acid in acetic acid electrolyte was used for the first-stage, while $2 \%$ perchloric acid in butoxyethanol was the second-stage electrolyte. To minimise oxidation, samples were washed often with ethanol and isopropanol and stored under rough vacuum (diaphragm pump) within five minutes of completing the second-stage electropolish.

Two types of CAMECA ${ }^{\mathrm{TM}}$ Local Electrode Atom Probe (LEAP) instruments were used for these experiments, a LEAP 3000X HR and a LEAP 5000XR. Every effort was made to keep the experimental parameters comparable across the two instruments and in particular the laser calibration study is described below. The LEAP 5000XR has an increased detector efficiency from 0.37 for the LEAP $3000 \mathrm{X}$ HR to 0.53 , and is equipped with a UV laser, which enables a smaller laser spot size to be produced compared to the green laser utilised by the LEAP $3000 \mathrm{X}$ HR. The laser spot size on the LEAP 5000XR is 3 times smaller, and so the power density is approximately 9 times greater.

To induce field evaporation of the samples, laser pulse mode was used, with the pulse frequency 
at $200 \mathrm{kHz}$ and the specimen temperature was set to $50 \mathrm{~K}$. Laser pulse mode was used as it maintains a relatively lower electric field on the sample and thus decreases stresses applied to the tip. This increased the M50 yield of specimen to be successfully analysed by reducing the likelihood of the brittle material fracturing and the intense electric field [26]. The main disadvantage of this experimental approach is the addition of "thermal tails" to the peaks in the mass spectrum which can reduce mass resolution. For M50, this mainly affects the molybdenum peaks overlapped by the thermal tail of iron peaks between 28-29 Da. The composition error that results from mass-tocharge-state ratio peak-overlap is significantly reduced by carrying out a deconvolution of relative contributions to the peak from the overlapping species based upon natural isotopic abundances and analysis of adjacent non-overlapping peaks [26]. The deconvolution error in the composition is less than $\pm 0.5 \%$ for the main alloying elements in M50.

As the laser energy is the key parameter in this experiment, affecting the measured composition, in order to determine the optimum laser conditions, we evaporated a single IM-M50 sample in the LEAP 3000X HR, varying the laser energy systematically with $0.1 \mathrm{~nJ}$ increments, starting from 0.1 $\mathrm{nJ}$ and reaching the maximum of $0.6 \mathrm{~nJ}$ laser energy, with 1 million ions pulse-evaporated at each laser energy step. The carbon concentration showed a minimum of 21 at.\% at 0.2 and $0.6 \mathrm{~nJ}$, rising to a maximum of 25 at. $\%$ at $0.4 \mathrm{~nJ}$. The concentration was normalised by the number of atoms, so the decreasing carbon content measured between 0.4-0.6 $\mathrm{nJ}$ in the carbides is likely due to an increased number of carbon multiples, as also reported by [29]. Thus $0.4 \mathrm{~nJ}$ was deemed the optimum laser energy to use for the most accurate carbon composition for the LEAP $3000 \mathrm{X}$ HR instrument, as it balances a high mass resolving power whilst ensuring the number of carbon multiple-hits does not increase significantly.

The laser spot size in the LEAP 5000XR is 3 times smaller than on the LEAP $3000 \mathrm{X}$ HR, thus the power density is 9 times greater. Hence, as a first rough approximation, in order to have similar evaporation conditions in the LEAP 5000XR, the laser energy used on the LEAP 3000X HR needs to be divided by a factor of 9. Our calibration experiment on the LEAP 5000XR showed that $44 \mathrm{pJ}$ laser energy yields similar ratios of $\mathrm{Cr}(26 \mathrm{Da})$ to $\mathrm{Cr}^{2}(52 \mathrm{Da})$ and that of $\mathrm{Fe}$ (28 
Da) to $\mathrm{Fe}^{2}(56 \mathrm{Da})$ to that of the LEAP $3000 \mathrm{X}$ HR datasets. As this is a strong indication of similar evaporation fields at the sample tip, $44 \mathrm{pJ}$ laser energy was selected as optimum for the LEAP 5000XR instrument. Preferential lateral heating to one side of the specimen by the laser was not observed to be a significant issue for either atom probe instrument used in the study.

After atom probe data collection, the evaporated samples were reconstructed using the standard IVAS $^{\mathrm{TM}}$ software suite. The voltage mode reconstruction method was used, as described by Gault et al. [26]. Details of this procedure are also discussed in [30]. As described below, a number of samples were examined before evaporation using diffraction-contrast transmission electron microscopy. Having the prior knowledge of the sample shape, distribution of carbides and other features within the microstructure from TEM helped to adjust the reconstruction parameters and thereby calibrate the spatial accuracy of the reconstruction.

TEM was carried out on a select number of M50 samples prior to APT analysis. A JEOL 2100 TEM, operated at an accelerating voltage of $200 \mathrm{kV}$, was used. As-electropolished APT samples were mounted in a Fischione tomography holder. Diffraction measurements were all performed at $12 \mathrm{~cm}$ camera length, calibrated using a standard sample of gold nanoparticles on amorphous carbon. Various microstructural features were imaged using diffraction-contrast TEM. Selected area diffraction patterns were inspected across the allowed tilting range of the holder. Diffraction peaks of interest were successively tilted to the optical axis and selected by a small objective lens aperture to form dark-field images. Diffraction patterns were analysed using JEMS software [31]. 


\section{Results}

The APT atom maps of a representative M50 sample are shown in Figure 1. A large plateshaped carbide contains mostly iron, while smaller 20-50 nm rod-shaped carbides contain chromium and molybdenum. These appear to be about the size and morphology expected of the $\mathrm{M}_{2} \mathrm{C}$ secondary carbides according to AP-FIM from $[15,25]$. Figure 2 uses an isoconcentration surface of 10 at.\% carbon to better highlight the morphology and orientation of the carbides.

Three different carbide compositions were observed in the M50 APT samples, along with the edge of a residual vanadium-rich carbide, which is discussed for comparison. The residual primary V-rich carbides are much larger in size and have small number density. Hence, we only encountered one of these at the edge of one of the datasets. Note that this carbide has been analysed, however, the corresponding reconstruction is not visualised here. Close-ups of two other types of secondary precipitates are shown in Figure $2 b$ and $c$. The composition of the main alloying elements is plotted across the matrix-carbide interface for each of these four carbides in Figure 3, and shows the wide composition variation between different types of carbides. The composition profile shown in Figure $3 \mathrm{a}$ is from the residual primary V-carbide, included for comparison.

It was challenging to select the isoconcentration surface value necessary for calculating the carbide composition, as apparent density variations (an APT artefact) caused large composition fluctuations in individual carbides. This problem was reduced by taking an average of all the carbides of that type in the sample, then plotting a proximity histogram (Figure 3). To measure the composition in the centre of the carbide, the isoconcentration surface was optimised to select as little of the carbide-matrix region not too few atoms remaining 
limiting the counting statistics. Given this necessary compromise, the interior of the carbide is defined as the point where the carbon content begins to plateau on the proximity histogram.. The average compositions are given in Table 3 . This shows that the three secondary precipitates have carbon contents near to the stoichiometric $\mathrm{M}_{2} \mathrm{C}, \mathrm{M}_{4} \mathrm{C}_{3}$ and $\mathrm{M}_{3} \mathrm{C}$ compositions.

The small M50 section containing $\mathrm{M}_{2} \mathrm{C}$ carbides in Figure $2 \mathrm{~b}$ demonstrates the challenging task of defining the carbide shape. While some of the carbides appear to be rod-shaped, in general they are very irregular. In many cases the carbides in the APT reconstruction also seem to be an interconnected network rather than individual precipitates. Whilst the average width and length can be measured, it is difficult to report a size with any physical meaning. Volume and volume fraction $\left(\mathrm{V}_{\mathrm{f}}\right)$ are the best way to compare relative carbide size and abundance. The average carbide volume, measured using the same carbon isoconcentration surface as for the composition calculations, was $40 \pm 20 \mathrm{~nm}^{3}$. This figure masks a large variation. While $70 \%$ of the carbides were under $60 \mathrm{~nm}^{3}$, the next $20 \%$ of the carbides were under $140 \mathrm{~nm}^{3}$ and the three largest carbides were over $500 \mathrm{~nm}^{3}$ in volume. No statistically significant correlations were found between carbide volume and composition.

$V_{f}$ is difficult to extract from APT. To eliminate the effect of apparent density differences to which carbide analyses in APT are typically prone, to calculate $\mathrm{V}_{\mathrm{f}}$, the number of precipitate atoms is divided by the total number of atoms in the sample. A 2 at.\% carbon isoconcentration surface defined the carbides for this measurement, to include as many of the carbide atoms and as few of the matrix atoms as possible. The weighted average $V_{f}$ for the three secondary carbides is given in Table 4. Due to the relatively low isoconcentration surface value, the $V_{\mathrm{f}}$ measurements are upper-bound values.

The APT reconstruction of sample 1, shown in Figure 4a contains a phase with the near-cementite composition. This sample was also examined via TEM in Figure 4b. The diffraction pattern that 
corresponds to this dark-field TEM is superimposed with a simulated cementite pattern (zone axis $=111)$ [32] in Figure 4d. The $(\overline{2} 20)$ reflection of cementite overlaps the $(\overline{1} 10)$ reflection in the simulated martensite pattern (zone axis $=113$ ) in Figure 4e, indicating an orientation relationship that can be summarised as:

$$
\begin{aligned}
& {[113]_{\alpha^{\prime}} \|[111]_{\theta}} \\
& (\overline{1} 10)_{\alpha^{\prime}} \|(\overline{2} 20)_{\theta}
\end{aligned}
$$

The same orientation relationship was first reported between cementite and ferrite by Zhong et al. [33]. The ferrite and martensite have very similar crystal structures in M50. The a and b axes are identical, while the martensite c-axis is $2.93800 \AA$, only $2.4 \%$ larger than the ferrite c-axis, which is 2.86790A. This near-cubic martensite has been reported in other steels after tempering [34-36].

The TEM dark-field image of sample 2 in Figure 5a highlights two precipitates corresponding to the two carbides in the APT sample with the near-cementite composition. These precipitates can be identified as cementite in TEM, as the 201 reflection $(2.21 \AA)$ of the cementite structure is an allowed reflection [32]. The composition is also the same as that observed in the case of cementite in sample 1 (Figure 4). Overlaying the atom map containing the cementite particles with the darkfield TEM image in Figure 5d shows how TEM enables calibration of the APT reconstructions. The particle separation distance in TEM helped adjust the spatial constraints of the APT reconstruction, which reduces uncertainties in characterising the secondary carbides.

Secondary carbides were identified by measurement of their composition in the samples that were also imaged in TEM. The APT reconstructions have been correlated to the TEM images.

The TEM dark-field image of sample 1 in Figure 6a shows rod-shaped carbides in two 
orientations at a small misalignment and a diffuse region of intensity across the top of the sample. Two low-intensity diffraction spots were captured in the objective aperture (Figure 6a inset), with $2.18 \AA$ and $3.16 \AA$ d-spacings. These spots are thought to correspond to the rod-shaped carbides, however the precipitate crystal structure could not be analysed further as no other carbide reflections were identified. Although the carbides were not identified from TEM, the small rod-shaped precipitates could correspond to the two plate-shaped precipitates with the near-M $\mathrm{M}_{2} \mathrm{C}$ composition as measured by APT. The $2.18 \AA$ reflection has already been identified as cementite, as detailed above and in Figure 4. The $3.16 \AA$ reflection is therefore more likely to correspond to the secondary carbides, as the spot is streaked in reciprocal space perpendicular to the precipitate elongation axis [28].The dark-field TEM images of sample 2 in Figure 7a show laths corresponding to the lines of carbides in the APT image with the near- $\mathrm{M}_{2} \mathrm{C}$ composition in Figure 7c. Again, the crystallography of the carbides could not be identified from the diffraction patterns as only the $1.65 \AA$ spot was found to correspond to the carbides. However, the presence of the diffraction peak means it is possible to conclude that the carbon regions are indeed carbides and not merely carbon-segregation to dislocations. Additionally, the lines of carbides contribute to the same $1.65 \AA$ diffraction spot, suggesting they have a very similar orientation. This is supported by the APT reconstruction, where the carbides are aligned in parallel planes. This is seen in Figure 7c, and more clearly in Figure 5c which corresponds to the same sample. This indicates some preferred orientation relationship with the matrix.

\section{Discussion}

Three secondary carbides have been observed in APT characterisation of M50, which have compositions close to the stoichiometric $\mathrm{M}_{2} \mathrm{C}, \mathrm{M}_{4} \mathrm{C}_{3}$ and $\mathrm{M}_{3} \mathrm{C}$. The measured carbon concentration 


\begin{abstract}
of the near- $\mathrm{M}_{2} \mathrm{C}$ carbides was 30.1 at.\%. Bridge et al. [21] measured the composition of these same carbides as $(\mathrm{Mo} 0.53 \mathrm{Fe} 0.20 \mathrm{Cr} 0.27)_{2} \mathrm{C}$. This is slightly different to the $(\mathrm{Mo} 0.30 \mathrm{Fe} 0.27 \mathrm{Cr} 0.35 \mathrm{~V} 0.08)_{2} \mathrm{C}$ in this study, as molybdenum is lower and iron, chromium and vanadium are correspondingly higher. It can be assumed that APT is likely more accurate than the electrolytic extraction methods used by Bridge et al. [21].
\end{abstract}

There is evidence that some of the $\mathrm{M}_{2} \mathrm{C}$ carbides appeared to contain less carbon and molybdenum but more chromium, however this study measured the average composition of all the carbides of one type in the sample and further study of individual carbides is required to determine whether these are different carbides.

The composition of the near- $\mathrm{M}_{4} \mathrm{C}_{3}$ carbides was 39.0 at.\% carbon, 20.2 at.\% vanadium and 24.2 at. $\%$ molybdenum on average, compared to the residual vanadium carbide, which contained 1 at. $\%$ more carbon, 14 at.\% more vanadium and correspondingly less iron, molybdenum and chromium. The residual carbides reduce the vanadium available in the matrix during tempering, resulting in the lower vanadium content of the secondary carbides and the correspondingly high molybdenum content $[22,37]$. This has been observed in AP-FIM studies of other high-speed steels [14, 15, 25]. The high Mo: $\mathrm{V}$ ratio is likely to greatly increase the hydrogen trapping capabilities of the $\mathrm{M}_{4} \mathrm{C}_{3}$ carbides, as a large molybdenum content increases the coherency strains with the lattice, to which hydrogen preferentially segregates [38]. Within the confidence interval defined in Table 5, the carbon content of the near- $\mathrm{M}_{4} \mathrm{C}_{3}$ lies between the expected range of $\mathrm{M}_{1.33} \mathrm{C}$ (i.e. $\mathrm{M}_{4} \mathrm{C}_{3}$ ) and $\mathrm{MC}$, but is closer to the substoichiometric $\mathrm{M}_{4} \mathrm{C}_{3}$, which is the more commonly reported composition $[11,22-24]$. 
Secondary cementite was also detected, with 3.5 at.\% lower carbon than the expected 25 at.\%. The $\mathrm{M}_{2} \mathrm{C}$ and $\mathrm{M}_{4} \mathrm{C}_{3}$ secondary carbide composition measurements had similar carbon deficiencies, as reported in Table 3 . The carbon variation from the expected values is statistically significant if the composition lies outside of a confidence level of three times the standard error, which is listed in Table 5. For non-trace elements, the standard error is $\sigma / \sqrt{n}$ where $n$ is the number of measurements made. The carbon-deficiency is statistically significant for the $\mathrm{M}_{2} \mathrm{C}$ and $\mathrm{M}_{3} \mathrm{C}$ carbides, but not for the $\mathrm{M}_{4} \mathrm{C}_{3}$ carbides as only two carbides were measured, which is the source of the relatively large standard error. Any systematic errors would not be demonstrated by this analysis.

It is important to determine if the carbon-deficiency is an APT artefact. Despite the measured carbon-deficiency of cementite in APT, TEM conclusively identified the cementite using a diffraction pattern that assumed a stoichiometric composition. Cementite has been used as a composition calibration phase in APT [29], which may suggest the secondary carbides are also stoichiometric. However, the carbon-deficiencies may not be related.

The cementite forms first during tempering [23]. The carbon segregation then assists nucleation of $\mathrm{M}_{2} \mathrm{C}$ and $\mathrm{M}_{4} \mathrm{C}_{3}$ carbides, which are more stable, so grow at the expense of the cementite $[18,39]$. The cementite is thus carbon-deficient because the plates are dissolving as the carbon diffuses to the vanadium carbides [23]. It also must be investigated if the secondary carbides appear to be carbondeficient due to APT artefacts. The true carbon composition is often underestimated in APT. This is likely due a combination of factors [29, 43-47]. Firstly due to the relatively high electric field required to evaporate carbon, most frequently it is detected in the form of multiple-hit detector 
events, i.e. multiple carbon atoms are evaporated from the surface of the specimen upon application of a single laser pulse. In this study $74 \%$ of the carbon was detected as a multiple hit in the LEAP 3000X HR analyses, and 85\% for those undertaken with the LEAP 5000XR. This results in multiple carbon ions arriving at the detector separated by extremely short intervals. Due to instrumental limitations the detector is unable to deal with this burst of ions and often the later arriving ions in the multiple hit event are lost to the analysis. This can result in a systematic erroneous decrease in the measured amount of carbon in the specimen. Other technique limitations such as the peak overlaps in the mass-to-charge-state spectrum (e.g. ${ }^{12} \mathrm{C}^{2+}$ and ${ }^{12} \mathrm{C}^{+}$) and local magnification spatial aberrations in the reconstruction that result in matrix atoms being incorporated into the analysis of the carbide also limit the APT carbon concentration measurements. However, this deviation in the composition measurement is difficult to quantify unless the phase has a well-known stoichiometry. Determining the carbide crystallography using the TEM techniques described herein, and attempting to establish whether they are stoichiometric is essential to assist further investigation into this carbon-deficiency.

The secondary carbides in APT correspond to distinguishable reflections in the TEM diffraction patterns, which confirms they are a distinct phase, not solid-solution carbon-enrichment to boundaries or dislocations. The carbides are challenging to identify in TEM without symmetrical zone axes. Two crystal structures were found with similar d-spacings. The first is orthorhombic $\eta$ $\mathrm{Fe}_{2} \mathrm{C}$ [36] while the second is hexagonal $\mathrm{Mo}_{2} \mathrm{C}$ [40]. Table 6 summarises similarities between the measured reflections and the proposed crystal structures, which have simpler compositions than those measured in this study. Therefore the carbides identified in APT may have a similar crystal structure, but altered lattice parameters due to the significant composition difference between the simple crystal structures $\mathrm{Fe}_{2} \mathrm{C}$ and $\mathrm{Mo}_{2} \mathrm{C}$, and the complex carbide composition found in M50 
The $\mathrm{M}_{2} \mathrm{C}$ carbide $\mathrm{V}_{\mathrm{f}}$ was measured as 0.15 in APT. Based on the bulk composition of the material, it is clear that this measurement must overestimate the volume fraction of $\mathrm{M}_{2} \mathrm{C}$. This is likely due to the culmination of a number of factors. This includes the choice of the isoconcentration surface $(2$ at.\% $\mathrm{C})$ to define the carbides for this measurement. The measured volume of the carbides will be highly dependent on choice of isoconcentration surface, and the low value used in this analysis may well result in the size of the individual carbides being overestimated. Furthermore, the imaging of the carbides will also be affected by local magnification induced trajectory aberrations that lead to a kind of defocussing effect in the APT reconstructions. This results in the carbides in the APT image as being erroneously less dense and larger in size. Finally, one must also take into account the very small sampling volumes investigated by APT, and thus sample-to-sample variations. This variation may also be exacerbated by certain regions of the M50 microstructure being more readily analysed in the APT experiment than others (e.g. large primary carbides), possibly further biasing the analysis to higher volume fractions of $\mathrm{M}_{2} \mathrm{C}$. Bridge et al. [21] estimated a weight fraction of these carbides as $0.038-0.042$. Assuming a carbide density of $8.9 \mathrm{~g} / \mathrm{cm}^{3}[41]$, this gives a $V_{f}$ of 0.045 . This is significantly lower than $V_{f}$ calculated by APT. Despite the limitations of the APT measurement, this difference is most likely because it is easier to identify secondary carbides using APT. In contrast, the $V_{f}$ of the $M_{4} C_{3}$ carbides was only $7.1 \times 10^{-5}$. The $M_{4} C_{3}$ carbides were only observed in one sample, so overall this $\mathrm{V}_{\mathrm{f}}$ is most likely of limited precision. The $\mathrm{M}_{2} \mathrm{C}$ carbides were observed in every M50 sample studied (which were randomly selected during electropolishing), suggesting a higher $\mathrm{M}_{2} \mathrm{C}$ abundance even if $\mathrm{V}_{\mathrm{f}}$ measurements are inaccurate. The preferential formation of $\mathrm{M}_{2} \mathrm{C}$ compared to $\mathrm{M}_{4} \mathrm{C}_{3}$ is partially due to the high molybdenum and chromium 
alloy content relative to vanadium $[15,23,42]$. It is also due to the residual carbides, which reduce the vanadium available during tempering [14].

This $\mathrm{V}_{\mathrm{f}}$ difference has potential interesting implications for research into HE-resistance. The rigorously characterised $\mathrm{M}_{2} \mathrm{C}$ carbides in $\mathrm{M} 50$ are reported to be hydrogen traps [23]. However, vanadium carbides are more effective at trapping hydrogen than $\mathrm{Mo} 2 \mathrm{C}$, particularly when the vanadium carbides contain significant molybdenum [22, 23, 38]. The effect of this $V_{f}$ difference must be further investigated to determine its implications on the HE-resistance of M50 and whether the HE-resistance of steels containing secondary carbides could be optimised by varying the relative abundance of different carbide types.

Some modifications to the M50 composition and processing could be made by decreasing the molybdenum and chromium content. In addition, novel heat-treatments could be considered, such as those used by Szost et al. [11] to produce secondary vanadium carbides in a new bearing alloy called $100 \mathrm{Cr} 6+\mathrm{V}$, which have been shown to increase hydrogen trapping. However, care must be taken during any modifications to ensure the secondary hardness is unaffected, particularly at elevated temperatures otherwise the steel would be ineffective for bearing applications. Dissolving the primary vanadium carbides by adding a one-minute temperature spike to $1200^{\circ} \mathrm{C}$ after austenisation, as carried out by Szost et al. [11] could limit the number of residual carbides and encourage the formation of secondary vanadium carbides in M50.

\section{Conclusions}

A combination of APT and TEM has been used to investigate the secondary carbides in M50. 


\begin{abstract}
Three secondary carbide types were identified in M50 using APT: $\mathrm{M}_{2} \mathrm{C}, \mathrm{M}_{4} \mathrm{C}_{3}$ and $\mathrm{MC} . \mathrm{M}_{4} \mathrm{C}_{3}$ contained slightly more molybdenum than vanadium, while $\mathrm{M}_{2} \mathrm{C}$ contained almost equal proportions of molybdenum, chromium and iron. The secondary cementite was found to be carbondeficient, and is likely to be dissolving in favour of the nucleation and growth of stoichiometric $\mathrm{M}_{4} \mathrm{C}_{3}$ and $\mathrm{M}_{2} \mathrm{C}$. The $\mathrm{M}_{4} \mathrm{C}_{3}$ carbide volume fraction, $\mathrm{V}_{\mathrm{f}}=7.1 \times 10^{-5}$, was much lower than $\mathrm{M}_{2} \mathrm{C}, \mathrm{V}_{\mathrm{f}}$ $=0.15 \pm 0.03$, likely due to the composition and processing used for M50.
\end{abstract}

TEM confirmed the identification of cementite precipitates from APT, and demonstrated an orientation relationship of $[113]_{\alpha^{\prime}}\left\|[111]_{\theta},(\overline{1} 10)_{\alpha^{\prime}}\right\|(\overline{2} 20)_{\theta}$ between the cementite and martensite matrix. Smaller precipitates observed in TEM were correlated to secondary carbides in APT, although they were not conclusively identified in TEM, so simpler unit cells of $\eta-\mathrm{Fe}_{2} \mathrm{C}$ and $\mathrm{Mo}_{2} \mathrm{C}$ with similar diffraction patterns were presented that should aid future identification.

Optimising the APT-TEM correlative procedure will assist studies of complex alloys, particularly where previous literature is unavailable. The procedure should also be combined with deuterium charging of APT samples. This is a technique currently being developed to directly study deuterium accumulation at hydrogen trapping sites [24]. This would allow studies to correlate the microstructure, hydrogen trapping strengths and HE resistance in bearing steels. The knowledge can then be applied to other steels and other materials that prone to the effects of HE. 


\section{Acknowledgements}

The authors acknowledge the support of the EPSRC under the HEmS Programme Grant EP/L014742/1 and EP/M022803/1 the LEAP 5000XR for the UK National Atom Probe Facility. 


\section{Page 19 of 36}

1

2

3

4

5

6

7

8

9

10

11

12

13

14

15

16

17

18

19

20

21

22

23

24

25

26

27

28

29

30

31

32

33

34

35

36

37

38

39

40

41

42

43

44

45

46

47

48

49

50

51

52

53

54

55

56

57

58

59

60

\section{Tables}

Table 1: Hydrogen Trapping Energies of Secondary Carbides [8]

\begin{tabular}{|l|l|}
\hline Carbide & Energy $\left(-E_{\mathbf{b}} / \mathbf{k J ~ m o l}^{-1}\right)$ \\
\hline $\mathrm{V}_{4} \mathrm{C}_{3}$ & $33-35$ \\
\hline $\mathrm{Mo}_{2} \mathrm{C}$ & $11-12$ \\
\hline Cementite/ $\alpha^{\prime}$ Interface & $11-18$ \\
\hline
\end{tabular}


Table 2: M50 composition (wt.\%)

\begin{tabular}{|l|l|l|l|l|l|l|l|}
\hline & C & Cr & Mo & V & Si & Mn & Fe \\
\hline M50 & 0.84 & 4.15 & 4.20 & 0.97 & 0.19 & 0.20 & 89.14 \\
\hline
\end{tabular}

21
22
23
24
25
26
27
28
29
30
31
32
33
34
35
36
37
38
39
40
41
42
43
44
45
46
47
48
49
50
51
52
53
54
55
56
57
58
59
60




\section{Page 21 of 36}

1

2

3

4

5

6

7

8

9

10

11

12

13

14

15

16

17

18

19

20

21

22

23

24

25

26

27

28

29

30

31

32

33

34

35

36

37

38

39

40

41

42

43

44

45

46

47

48

49

50

51

52

53

54

55

56

57

58

59

60

Table 3: Average carbide composition. The error stated is \pm one standard error. No standard error is given for the composition of the residual vanadium carbide as only one was measured.

\begin{tabular}{ccccc} 
& Residual VC & $\mathbf{M}_{\mathbf{2}} \mathbf{C}$ & $\mathbf{M}_{\mathbf{4}} \mathbf{C}_{\mathbf{3}}$ & $\mathbf{M}_{\mathbf{3}} \mathbf{C}$ \\
\hline $\mathbf{C}$ & 40.2 & $30.1 \pm 0.6$ & $39.0 \pm 2.4$ & $21.5 \pm 0.3$ \\
$\mathbf{C r}$ & 4.4 & $23.4 \pm 0.8$ & $12.9 \pm 1.1$ & $11.1 \pm 2.3$ \\
$\mathbf{M o}$ & 18.5 & $20.0 \pm 0.6$ & $24.2 \pm 1.2$ & $3.1 \pm 0.4$ \\
$\mathbf{V}$ & 34.1 & $5.8 \pm 0.3$ & $20.2 \pm 2.1$ & $1.1 \pm 0.1$ \\
$\mathbf{S i}$ & 0.23 & $0.3 \pm 0.08$ & $<0.02$ & $0.15 \pm 0.02$ \\
$\mathbf{F e}$ & 1.6 & $18.6 \pm 0.8$ & $2.4 \pm 0.2$ & $62.0 \pm 2.7$
\end{tabular}


Table 4: Volume fraction of secondary carbides.

(No $\sigma$ is given for the $M_{4} C_{3}$ carbides, as they were only measured in one sample).

\begin{tabular}{|l|l|l|}
\hline $\mathbf{M}_{2} \mathbf{C}$ & $\mathbf{M}_{\mathbf{4}} \mathbf{C}$ & $\mathbf{M}_{\mathbf{3}} \mathbf{C}$ \\
\hline $0.15 \pm 0.03$ & $4.9 \times 10^{-4}$ & $0.04 \pm 0.01$ \\
\hline
\end{tabular}




\section{Page 23 of 36}

1

2

3

4

5

6

7

8

9

10

11

12

13

14

15

16

17

18

19

20

21

22

23

24

25

26

27

28

29

30

31

32

33

34

35

36

37

38

39

40

41

42

43

44

45

46

47

48

49

50

51

52

53

54

55

56

57

58

59

60

Table 5: Statistical analysis of carbon content in phases in M50 (at.\%)

\begin{tabular}{cccc} 
Phase & Expected C-content & Measured C-content & Confidence Interval \\
\hline M3C & 25.0 & 21.5 & 0.8 \\
M2C & 33.3 & 30.1 & 1.8 \\
M4C3 & 42.9 & 39.0 & 7.2 \\
\hline
\end{tabular}


Table 6: Comparison between TEM diffraction patterns and possible crystal structures

\begin{tabular}{cc|cc|cc}
\multicolumn{2}{c|}{$\begin{array}{c}\text { Measured Reflections } \\
\text { d-spacing }(\AA)\end{array}$} & \multicolumn{2}{|c|}{ Figures $^{(\AA-F e} \mathbf{C}[36]$} & \multicolumn{2}{c}{$\mathbf{M o}_{2} \mathbf{C}[40]$} \\
\hline $3.16 / 3.17$ & 6 & 3.17 & $(110)$ & - & - \\
$2.15 / 2.17$ & 6 & 2.15 & $(020)$ & - & - \\
1.65 & 7 & $1.67 / 1.61$ & $(211) /(121)$ & 1.74 & 102 \\
\hline
\end{tabular}




\section{References}

[1] J. Gegner, "Tribological aspects of rolling bearing failures," in Tribology - Lubricants and Lubrication (K. Chang-Hung, ed.), pp. 33-94, 2011.

[2] H. Bhadeshia, "Steels for bearings," Progress in Materials Science, vol. 57, no. 2, pp. 268435, 2011.

[3] M. A. Stopher and P. E. J. Rivera-Diaz-del-Castillo, "Hydrogen embrittlement in bearing steels," Materials Science and Technology, vol. 32, no. 3, pp. 1-10, 2016.

[4] J. Ciruna and H. Szieleit, "The effect of hydrogen on the rolling contact fatigue life of AISI 52100 and 440C steel balls," Wear, vol. 24, no. 1, pp. 107-118, 1973.

[5] B. Allison, Evolution of mechanical properties of M50 bearing steel due to rolling contact fatigue. PhD thesis, University of Florida, 2013.

[6] I. M. Robertson, P. Sofronis, A. Nagao, M. L. Martin, S. Wang, D. W. Gross, and K. E. Nygren, "Hydrogen embrittlement understood," Metallurgical and Materials Transactions $B$, vol. 46, no. 3, pp. 1085-1103, 2015.

[7] W. H. Johnson, "On some remarkable changes produced in iron and steel by the action of hydrogen and acids," Proceedings of the Royal Society of London, vol. 23, pp. 168-179, 1874.

[8] H. Bhadeshia, "Prevention of Hydrogen Embrittlement in Steels," ISIJ International, vol. 56, no. 1, pp. 24-36, 2016.

[9] R. Oriani, "The diffusion and trapping of hydrogen in steel," Acta Metallurgica, vol. 18, no. 1, pp. 147-157, 1970.

[10] G. M. Pressouyre, "Hydrogen traps, repellers, and obstacles in steel; consequences on hydrogen diffusion, solubility, and embrittlement," Metallurgical Transactions A, vol. 14, no. 10, pp. 2189-2193, 1983. 
[11] B. A. Szost, R. H. Vegter, and P. E. J. Rivera-D' 1az-del Castillo, 'Developing bearing steels combining hydrogen resistance and improved hardness," Materials and Design, vol. 33, pp. 499-506, 2012.

[12] T. Nishikawa, N. Hayashi, and A. Hayakawa, "Technical trend of aircraft bearings," NTN Technical Review, vol. 82, pp. 83-87, 2014.

[13] C. Feng, G. Chow, S. Rangarajan, X. Chen, K. Gonsalves, and C. Law, "TEM and HRTEM characterization of nanostructured M50 type steel," Nanostructured Materials, vol. 8, no. 1, pp. 45-54, 1997.

[14] K. Stiller, L.-E. Svensson, P. Howell, W. Rong, H.-O. Andrén, and G. Dunlop, "High resolution microanalytical study of precipitation in a powder metallurgical high speed steel," Acta Metallurgica, vol. 32, no. 9, pp. 1457-1467, 1984.

[15] H. Fischmeister, S. Karagöz, and H. Andrén, “An atom probe study of secondary hardening in high speed steels," Acta Metallurgica, vol. 36, no. 4, pp. 817-825, 1988.

[16] H. Andrén, S. Karagöz, C. Guangjun, L. Lundin, and H. Fischmeister, "Carbide precipitation in chromium steels," 1991.

[17] T. Kinkus and G. Olson, "Microanalytical evaluation of a prototype stainless bearing steel," Surface Science, vol. 266, no. 1-3, pp. 391-396, 1992.

[18] R. Thomson, "Characterization of carbides in steels using atom probe field-ion microscopy," Materials Characterization, vol. 44, no. 1-2, pp. 219-233, 2000.

[19] J.-H. Kang and P. Rivera-D'1az-del Castillo, "Carbide dissolution in bearing steels," Computational Materials Science, vol. 67, pp. 364-372, 2013.

[20] A. T. W. Barrow and P. E. J. Rivera-D'1az-Del-Castillo, "Nanoprecipitation in bearing steels," Acta Materialia, vol. 59, pp. 7155-7167, 2011.

[21] J. E. Bridge, G. N. Maniar, and T. V. Philip, "Carbides in M-50 high speed steel," Metallurgical Transactions, vol. 2, no. 8, pp. 2209-2214, 1971. 
[22] T. Baker, "Processes, microstructure and properties of vanadium microalloyed steels," Materials Science and Technology, vol. 25, no. 9, pp. 1083-1107, 2009.

[23] S. Yamasaki and H. K. D. H. Bhadeshia, "Modelling and characterisation of V4C3 precipitation and cementite dissolution during tempering of $\mathrm{Fe}-\mathrm{C}-\mathrm{V}$ martensitic steel," Materials Science and Technology, vol. 19, no. 10, pp. 1335-1343, 2003.

[24] J. Takahashi, K. Kawakami, and T. Tarui, "Direct observation of hydrogen-trapping sites in vanadium carbide precipitation steel by atom probe tomography," Scripta Materialia, vol. 67, no. 2, pp. 213-216, 2012.

[25] W. Rong, H. Andrén, H. Wisell, and G. Dunlop, "The role of alloy composition in the precipitation behaviour of high speed steels," Acta Metallurgica et Materialia, vol. 40, no. 7, pp. 1727-1738, 1992.

[26] B. Gault, M. P. Moody, J. M. Cairney, and S. P. Ringer, Atom Probe Microscopy. Springer, 1 ed., 2012.

[27] B. A. Szost and R. H. Vegter, "Hydrogen trapping mechanisms in nanostructured steels," Metallurgical and Materials Transactions A, vol. 44, no. 10, pp. 4542-4550, 2013.

[28] D. Brandon and W. D. Kaplan, Transmission Electron Microscopy. New York: Springer Science \& Business Media, 2 ed., 2008.

[29] H. S. Kitaguchi, S. Lozano-Perez, and M. P. Moody, "Quantitative analysis of carbon in cementite using pulsed laser atom probe," Ultramicroscopy, vol. 147, pp. 51-60, 2014.

[30] B. Gault, D. Haley, F. de Geuser, M. Moody, E. Marquis, D. Larson, and B. Geiser, “Advances in the reconstruction of atom probe tomography data," Ultramicroscopy, vol. 111, no. 6, pp. 448 - 457, 2011. Special Issue: 52nd International Field Emission Symposium.

[31] P. Stadelmann, “JEMS JAVA electron microscopy software,” Accessed 17-12-2015.

[32] I. Wood, L. Vocadlo, K. Knight, D. Dobson, W. Marshall, G. Price, and J. Brodholt, “Thermal expansion and crystal structure of cementite, $\mathrm{Fe} 3 \mathrm{C}$, between 4 and $600 \mathrm{~K}$ determined by time- 
of-flight neutron powder diffraction," Journal ofApplied Crystallography, vol. 37, pp. 8290, 2004.

[33] N. Zhong, X. Wang, Z. Guo, and Y. Rong, "Orientation Relationships between Ferrite and Cementite by Edge-to-edge Matching Principle," Journal of Materials Science and Technology, vol. 27, no. 5, pp. 475-480, 2011.

[34] L. Chang, DPhil Thesis. PhD thesis, Oxford University, 1985.

[35] M. Perez, C. Sidoroff, A. Vincent, and C. Esnouf, "Microstructural evolution of martensitic 100Cr6 bearing steel during tempering: From thermoelectric power measurements to the prediction of dimensional changes," Acta Materialia, vol. 57, no. 11, pp. 3170-3181, 2009.

[36] Y. Hirotsu and S. Nagakura, "Crystal structure and morphology of the carbide precipitated from martensitic high carbon steel during the first stage of tempering," Acta Metallurgica, vol. 20, no. 4, pp. 645-655, 1972.

[37] R. Lagneborg, T. Siwecki, S. Zajac, and B. Hutchinson, "The role of vanadium in microalloyed steels," Scandinavian Journal of Metallurgy, vol. 28, no. 5, pp. 186-241, 1999.

[38] S. Yamasaki and H. Bhadeshia, "M4C3 precipitation in Fe-C-Mo-V steels and relationship to hydrogen trapping," Proceedings of the Royal Society A: Mathematical, Physical and Engineering Sciences, vol. 462, no. 2072, pp. 2315-2330, 2006.

[39] S. Yamasaki and H. K. D. H. Bhadeshia, "Modelling and characterisation of Mo 2 C precipitation and cementite dissolution during tempering of FeCMo martensitic steel," Materials Science and Technology, vol. 19, no. 6, pp. 723-731, 2003.

[40] K. Madhav Reddy, T. N. Rao, J. Revathi, and J. Joardar, "Structural stability of $\alpha / \beta-M o 2 C$ during thermochemical processing," Journal of Alloys and Compounds, vol. 494, no. 1-2, pp. 386-391, 2010.

[41] ESPI Metals, "Molybdenum Carbide Mo2C." http:/www.espimetals.com/ index.php/msds/675-molybdenum-carbide-mo2c, 2016. Accessed 23-052016.

[42] M. Grujicic, "Design of $\mathrm{M} 2 \mathrm{C}$ carbides for secondary hardening," in Innovations in Ultrahigh strength Steel Technology (G. B. Olson, M. Azrin, and E. S. Wright, eds.), pp. 
223-237, Watertown, Mass.: U.S. Army Laboratory Command, Materials Technology Laboratory, 1990.

[43] J. Takahashi, K. Kawakami, and Y. Kobayashi, "Quantitative analysis of carbon content in cementite in steel by atom probe tomography," Ultramicroscopy, vol. 111, no. 8, pp. 1233-8, 2011.

[44] W. Sha, L. Chang, G. Smith, and E. Mittemeijer, "Some aspects of atom-probe analysis of Fe-C and Fe-N systems," Surface Science, vol. 266, no. 1-3, pp. 416-423, 1992.

[45] M. Thuvander, J. Weidow, J. Angseryd, L.K.L. Falk, F. Liu, M. Sonestedt, K. Stiller and H.-O. Andrén, “Quantitative atom probe analysis of carbides”, Ultramicroscopy, vol 111, no. 6, pp. 604-608, 2011.

[46] J. Akré, F. Danoix, H. Leitner, P. Auger, "The morphology of secondary-hardening carbides in a martensitic steel at the peak hardness by 3DFIM," Ultramicroscopy. vol.109 no. 5, pp. 518-523, 2009.

[47] G. Da Costa, F. Vurpillot, A. Bostel, M. Bouet and B Deconihout, "Design of a delay-line position-sensitive detector with improved performance," Review of Scientific Instruments, vol. 76, no. 1, 013304, 2005.

[48] M. Herbig, D. Raabe, Y. J. Li, P. Choi, S. Zaefferer, and S. Goto, "Atomic-Scale Quantification of Grain Boundary Segregation in Nanocrystalline Material,"

Physical Review Letters, vol. 112, 126103, 2014.

[49] A.J. London, S. Lozano-Perez, M.P. Moody, S. Amirthapandian, B.K. Panigrahi, C.S. Sundar, C.R.M. Grovenor "Quantification of oxide particle composition in model oxide dispersion strengthened steel alloys," Ultramicroscopy, vol. 159, pp. 360-367, 2015.

[50] M. Meisnar, M. P. Moody, S. Lozano-Perez, “Atom probe tomography of stress corrosion crack tips in SUS316 stainless steels," Corrosion Science, vol. 98, pp. 661-671, 2015. 



Si

$\overline{20 \mathrm{~mm}}$

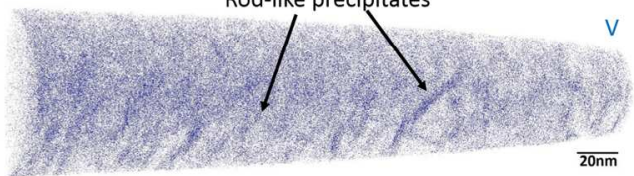

Figure 1: Atom maps of the iron matrix and the main alloying elements, showing rod-like carbides and a large plate-shaped precipitate. (From LEAP 3000) 
(a)


(b)

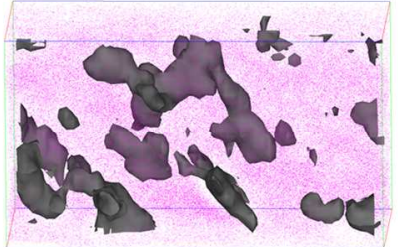

(c)

$\underline{10 \mathrm{~nm}}$

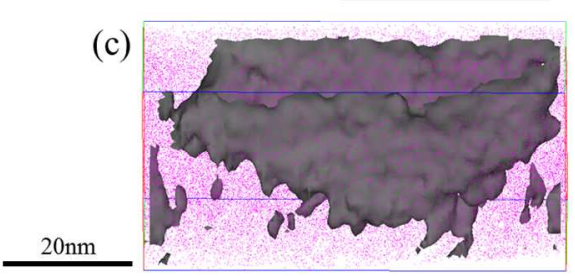

Figure 2: (a) A 10 at.\% carbon isoconcentration surface highlights the precipitates from Figure 1. The iron matrix is shown to illustrate the three-dimensional nature of this image. Close-up of regions of interest in this APT reconstruction highlight the presence of (b) secondary M2C carbides, and (c) section of Fe-rich plate-shaped cementite. 
(a)

(c)
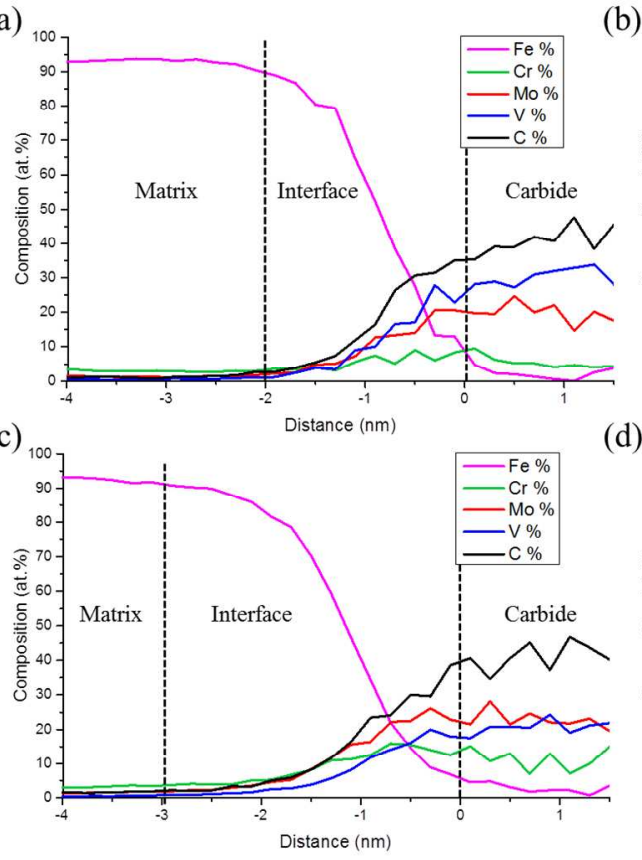

(b)

(d)
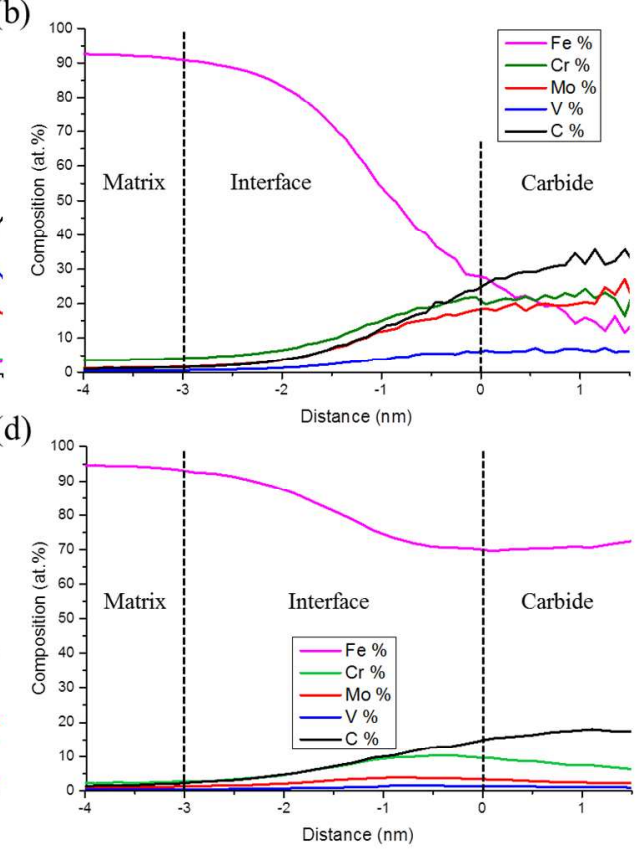

Figure 3: The chemical composition across the matrix-carbide interface is plotted in proximity histograms for (a) the residual vanadium carbide (isoconcentration surface $=35$ at. $\%$ carbon), (b) secondary M2C carbides (isoconcentration surface $=25$ at. $\%$ carbon), (c) secondary vanadium carbides (isoconcentration surface $=$ 40 at. \% carbon), (d) cementite (isoconcentration surface $=15$ at. $\%$ carbon). 

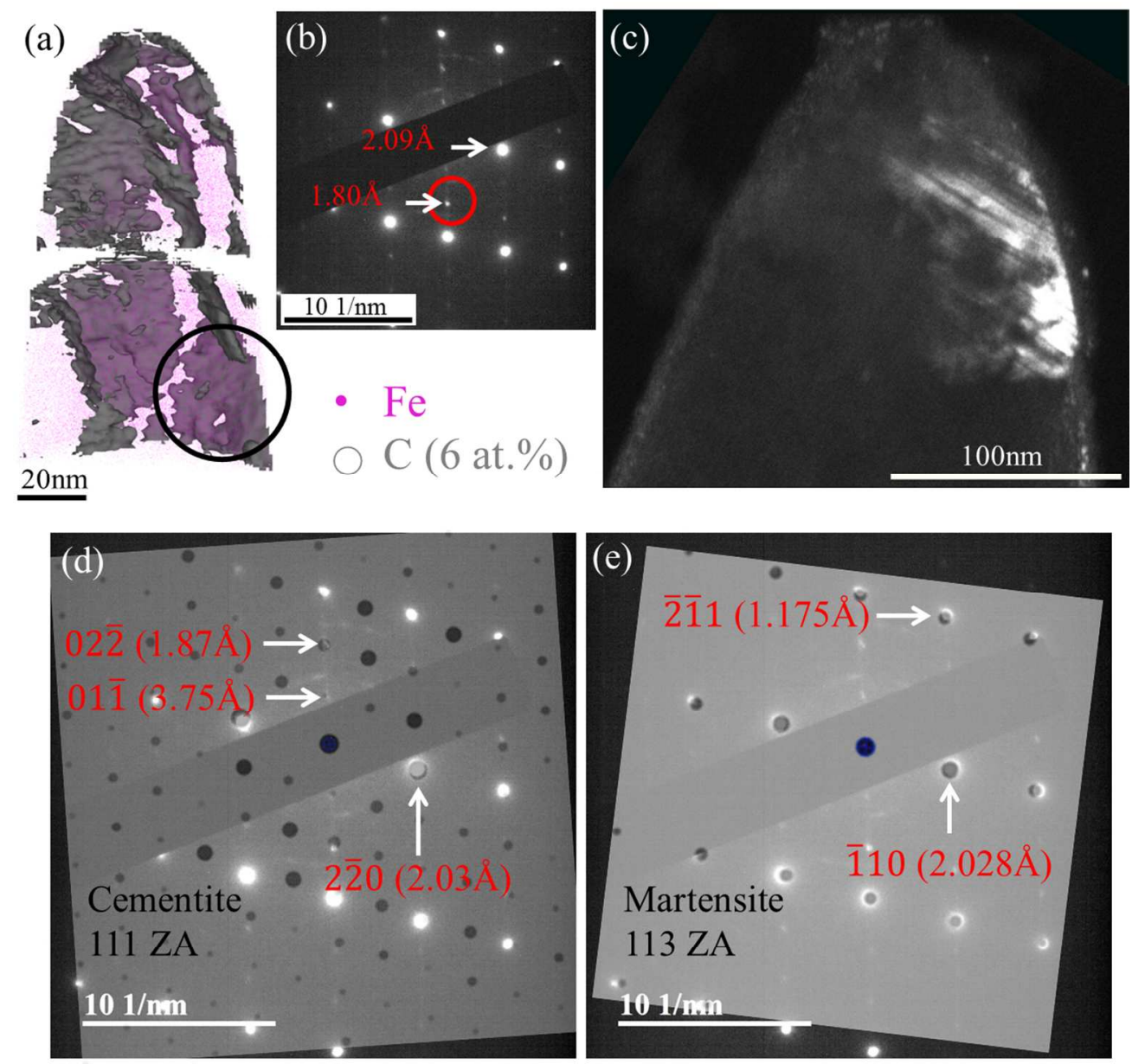

Figure 4: (a) APT reconstruction of sample 1 (From LEAP 3000). (b) Diffraction pattern showing the selected diffraction spot. The d-spacings on this diffraction pattern are the measured values. (c) Correlated dark-field TEM image. (d) Diffraction pattern overlaid with simulated diffraction patterns showing cementite, zone axis 111 , and (e) martensite, zone axis 113. Note: For (d) and (e ), the d-spacings on the overlaid patterns are the nominal values. 

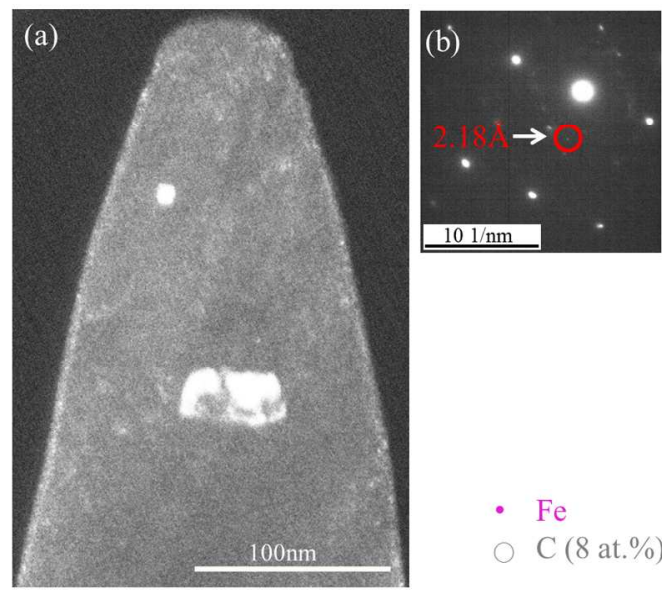

(c)

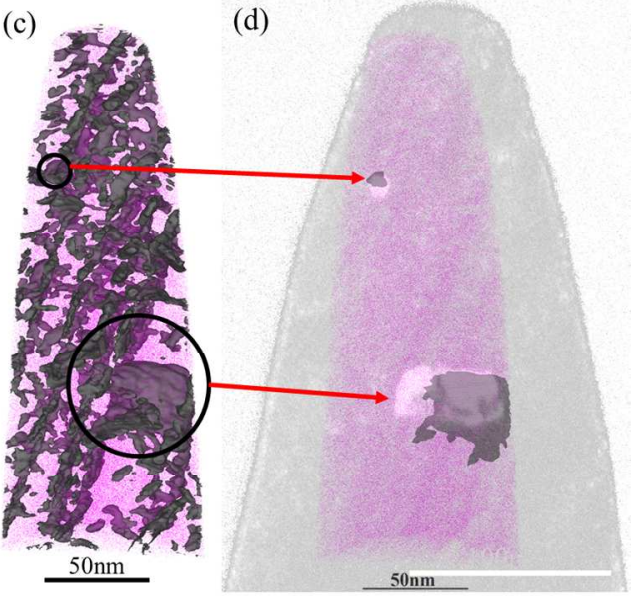

Figure 5: (a) TEM dark-field image of sample 2, with (b) selected diffraction spot. The $2.18 \AA$ reflection corresponds to $2.15 \AA$ in the simulated diffraction pattern of cementite. (c) Correlated APT orientation (Leap 5000 ). The two circled precipitates are cementite, while the lines of carbides were found to have the nearM2C composition and are discussed later. (d) The same APT orientation with only the near-cementite precipitates highlighted is superimposed onto the TEM image. 


\section{Page 35 of 36}
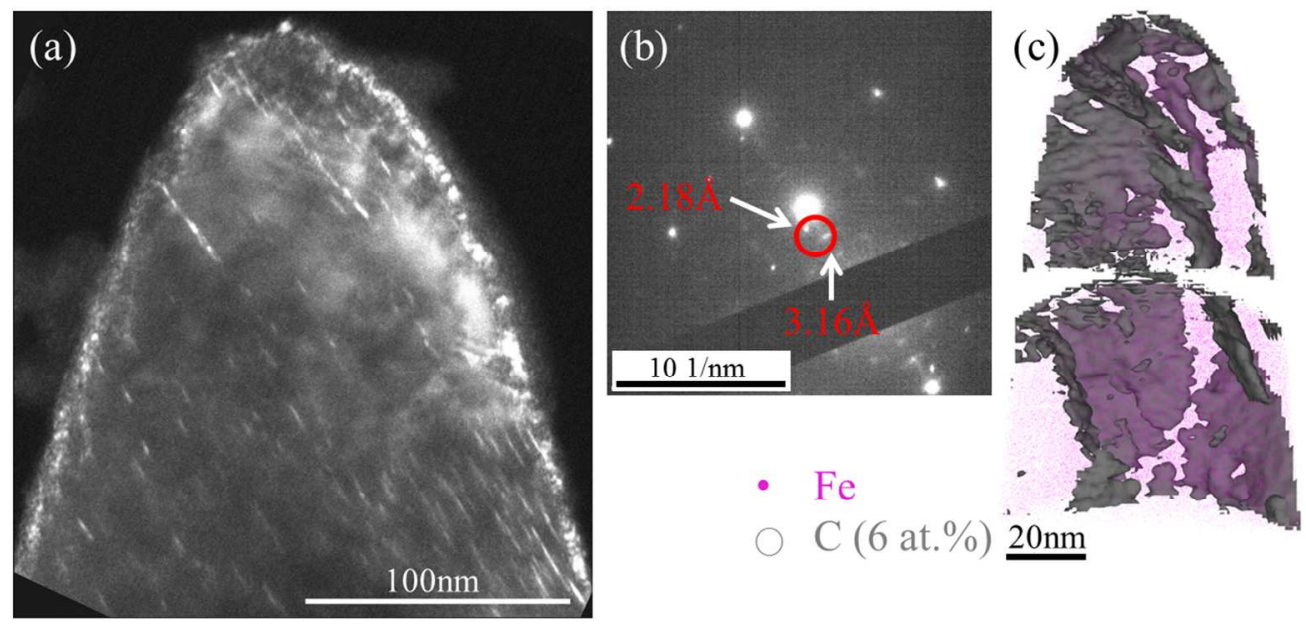

- $\mathrm{Fe}$

C $(6$ at. $\%) \underline{20 \mathrm{~nm}}$

Figure 6: (a) TEM dark-field image of sample 1, with (b) selected diffraction spots. The $3.16 \AA$ spot is elongated perpendicular to the precipitate elongation axis. (b) Correlated APT image (LEAP 3000). Note: APT image is in two sections because experiment was stopped and restarted. 


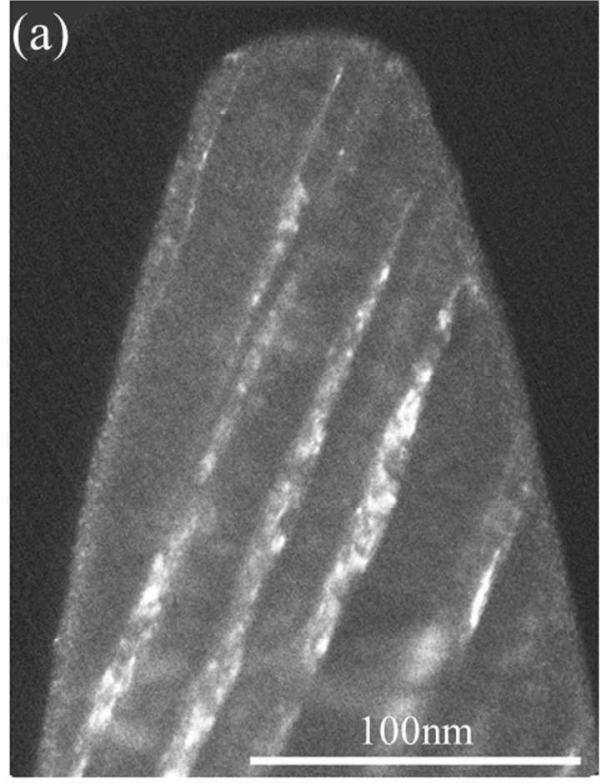

(c)

(b)

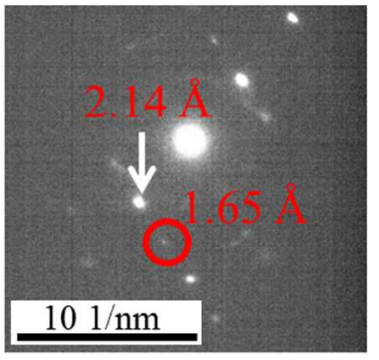

- $\mathrm{Fe}$

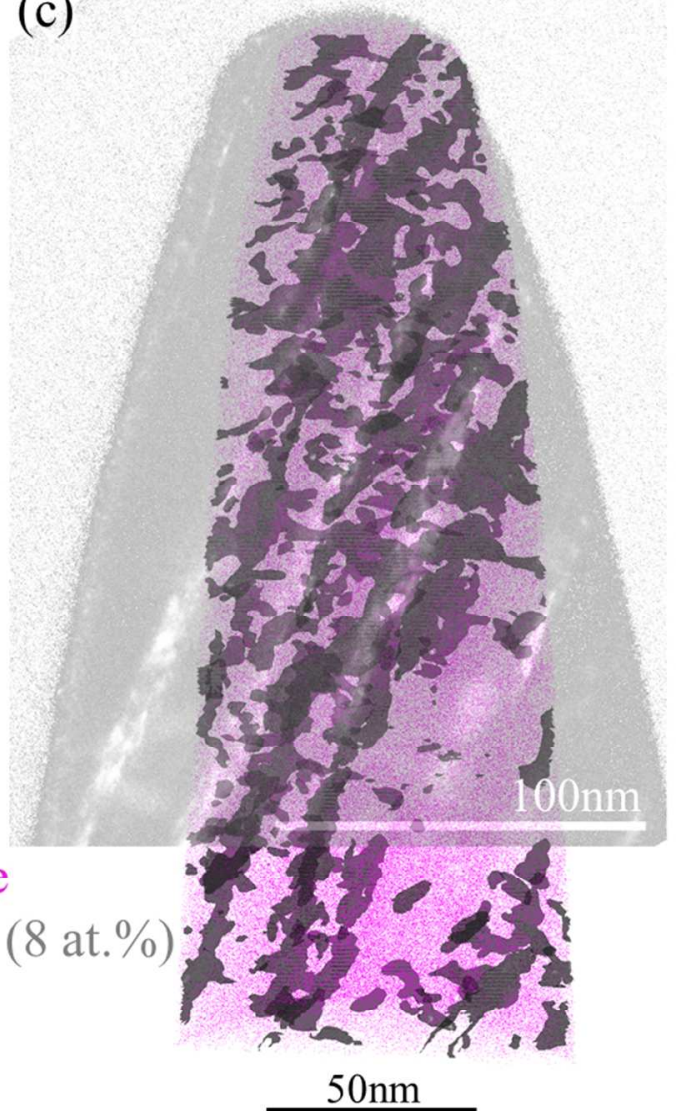

Figure 7: (a) TEM dark-field of the laths in sample 2, with (b) selected diffraction spots. (c) Correlated APT image overlaid with the TEM dark-field from (a) (LEAP 5000). 